\title{
Adherence to Combined Antiretroviral Therapy and Associated Factors Among People Living with HIV Attending Nekemte Specialized Hospital, Oromia, Ethiopia: A Cross-Sectional Study
}

This article was published in the following Dove Press journal: HIVIAIDS - Research and Palliative Care

\author{
Mulu Ejigu' \\ Zelalem Desalegn $\mathbb{D}^{2}$ \\ Befirdu Mulatu² \\ Getu Mosisa ${ }^{3}$ \\ 'CDC Project, East Wollega Zone Health \\ Office, Nekemte, Oromia, Ethiopia; \\ ${ }^{2}$ Department of Public Health, Institute \\ of Health Science, Wollega University, \\ Nekemte, Oromia, Ethiopia; ${ }^{3}$ School of \\ Nursing and Midwifery, Institute of \\ Health Science, Wollega University, \\ Nekemte, Oromia, Ethiopia
}

\begin{abstract}
Background: For people living with HIV, to have sustainable viral suppression and better clinical outcomes, they should have a high level of adherence to antiretroviral therapy. In the treatment of human immune deficiency, antiretroviral therapy adherence became the major challenge in both developed and developing countries. The level of antiretroviral therapy differs across the settings. This study aimed to assess the level of combined ART adherence and associated factors among adult people living with HIV attending Nekemte Specialized Hospital, Ethiopia.

Methods: The institution-based cross-sectional quantitative study was conducted from August 2017 to September 2017. A total number of 284 clients participated in the study and a simple random sampling technique was used to allocate study participants. Data were entered into Excel and exported to SPSS version 20 for analysis. Bivariate analysis was conducted to identify candidate variables for multivariate analysis at $\mathrm{p}$-value $<0.2$. Multiple logistic regression analysis was conducted to determine the predictors of non-adherence to ART. P-value $<0.05$ was considered to indicate statistical significance.
\end{abstract}

Results: About $81 \%$ of the study participants adhered to combined anti-retroviral therapy. Mentioned reasons for missing ART medications were simply forgot to take medication (44.4\%), lack of transportation (21\%), to avoid side effects $(11.4 \%)$, do not want significant others to notice taking medication (11.4\%) and felt sick (11.4\%). Not using reminder (AOR=4.98 $(1.65,15.02))$, poor knowledge on ART $(\mathrm{AOR}=2.79(1.49,5.25))$, and engaging in unprotected sexual intercourse $(\mathrm{AOR}=2.16(1.15,4.05))$ were significantly associated with non-adherence to combined ART.

Conclusion: About $81 \%$ of study participants adhered to combined ART, and poor knowledge about ART, engaging in unprotected sexual intercourse and not using the reminder were significantly associated with nonadherence to combined ART. Efforts to increase adherence levels should be encouraged.

Keywords: HIV patient, ART, combined ART adherence, Nekemte Specialized Hospital

\section{Introduction}

HIV becomes the major public health problem worldwide since its appearance, and the majority of infected people are living in Sub-Saharan Africa. ${ }^{1,2}$ ART is the base for comprehensive health sector response to Human Immunodeficiency Virus treatment, care, and support. Adherence of clients for their treatment plan near perfect is mandatory to keep the virus suppressed, as per World Health Organization guidelines. $^{3}$ 
Successful ART program is when the patient adheres, and retained in care. It has been expected that for ART treatment to be effective; adherence should be at least 95\%. High-level adherence is necessary for all HIVinfected people who are enrolled in chronic care services adhere to ART and OI medication and follow treatment plans. ${ }^{4}$

ART plays a pivotal role to maximize and sustain suppression of viral replication, restore immune function, minimize morbidity and mortality, improve quality of life and life expectancy. ${ }^{5}$

Globally, ART recommended for all HIV patients irrespective of CD4 count, WHO staging and clinical status. The focus of patient management has changed from identifying and managing early ARV related toxicities to test and treat strategy. To achieve sustained viral suppression over a lifetime, both long-term and short-term ART toxicities must be expected and overcome. The clinician must consider potential adverse effects when selecting an ARV regimen and a previous history of drug intolerances. ${ }^{6}$

Even though launching free accessibility of ART to several facilities in Ethiopia adherence is still challenging for ART programs, the test and start strategy has implemented in August 2016. ART should be initiated for all HIV (children, adolescents and adults) living with HIV immediately after HIV diagnosis, regardless of WHO clinical stage and CD4 cell count to impro1ve quality of care, improve access to HIV care and treatment for all and to achieve the sustainable development goal global targets of 390 s by $2020 .^{7}$ Adequate adherence preparation and assuring patient willingness as per the national guideline (2014) are important for all individuals before initiating ART. ${ }^{8}$

Failure to adhere cause major impacts on patients, family, caregivers, community, and also a high burden for providers, health facilities, health care systems, health plans, industry, and society. Poor drug adherence among PLHIV leads to drug resistance and failure, and then increase morbidity and mortality. They may be more complex than the first-line regimen. Second and third-line regimens require optimal adherence to sustain viral suppression more than the first-line regimen. ${ }^{9,10}$

Various studies worldwide showed poor adherence is common. Literature reviews that the level of adherence to antiretroviral therapy in Ethiopia look like findings in most of the SSA countries. In yirgalem $72.8 \%$, Gonder University and Felege Hiwot hospitals 82.7\%, Gobba Hospital $90.8 \%$, in Debre Markos Specialized hospital $88.6 \%$, JUSH $72.4 \% .^{9,11-14}$
This study was focused on different independent indicators in addition to self-report; to avoid overestimation of adherence and fabrications caused by self-report. In addition to self-report, the studies focus on viral load, pharmacy refill, patient card (schedule for appointment plan, comparing baseline CD4 cell count with current CD4 cell count). Therefore, this study aimed to assess the level of combined ART adherence and associated factors among adult PLHIV attending Nekemte Specialized Hospital, Ethiopia.

\section{Methods \\ Study Area}

The study was conducted at Nekemte Specialized hospital located in Nekemte town, $328 \mathrm{~km}$ from Addis Ababa, the capital city of Ethiopia. Nekemte town has six sub-cities; Derge, Bake Jema, Cheleleki, Kessso, Burka Jato, and Bakanisa Kesse. Nekemte town has 2 Specialized hospital (Nekemte Specialized hospital and Wollega University Specialized hospital), and 2 health centers (Nekemte health center and Cheleleki health center). Nekemte Specialized hospital was established in 1939 G.C. by Sweden missionary. The Hospital gives service for Nekemte town, East Wollega zone, West Wollega zone, KellamWollega zone, Horo Guduru Wollega zone, West Shawa zone, Benishangul region, and nearby Amhara region with a total population of 934,860 . The hospital has 178 beds for inpatient services. There is 294 clinical and administrative staff serving in the hospital (9 specialists, $23 \mathrm{MD}, 42 \mathrm{BSc}$ Nurses, 57 diploma Nurses, 58 other health professionals, and 24 administrative workers). The hospital gives all health services including ART for the community. ART was initiated in 2004 G.C. in the hospital. Currently, 2234 patients are receiving ART services in the hospital and 2051 of them were adults.

\section{Study Design and Period}

An institution-based cross-sectional study was used to assess ART adherence among HIV-infected adults on chronic care follow up in Nekemte Specialized hospital attendants. The study period was from August 2017 to September 2017.

\section{Study Population}

All PLHIV were the target group, and study populations were HIV-infected adults who were on chronic care follow up service in Nekemte Specialized hospital. 


\section{Sample Size and Sampling Techniques}

The sample size was determined by using a single population proportion formula, taking P-value $80 \%$, from the study conducted in Addis Ababa. ${ }^{15}$ The maximum sample size was calculated using marginal error $=0.05$, critical value $=1.96$ and $15 \%$ non-response rate which yielded a sample size of 284. A simple random sampling technique was used to draw study participants. First, the clients were given sequential order numbers; then, according to our inclusion criteria clients who were on ART for at least 6 months, age $>18$ years, and have an appointment during the data collection period were included. Then, by using a simple random sampling procedure, the participant's card was selected from the appointment calendar logbook by the lottery method.

\section{Data Collection}

Structured questionnaire was used to collect the data, ART register, patient folder (follow up, laboratory results, intake form). Three trained data collectors were assigned and carried out the face-to-face interviews in a separate room to address the demographic, socioeconomic, disclosure status, health care providers and health care system variables. Available clinical (WHO stage) and immunological (CD4 count) and viral load data were collected. The questionnaire was prepared in English and translated to "Afan Oromo" which is a regional working language then translated back to English to check for consistency.

\section{Ethics Approval and Consent to Participate}

Ethical clearance was obtained from Wollega University's research ethics review committee, and written informed consent was obtained from each study participant and the study was conducted in accordance with the Declaration of Helsinki. Permission from the town health office and Nekemte Specialized hospital was obtained. The privacy of participants was kept. Besides, the confidentiality of the results was ensured by assigning identification numbers during registration.

\section{Operational Definitions}

ART adherence: - is a patient's ability to follow a treatment plan, take medication at a prescribed time and follow instructions and restrictions regarding food and other follow up schedules.
Non-adherence to ART: - is the condition of missing dose, not following a treatment plan, instruction and restriction regarding food and other follow up schedule.

Combined ART Adherence: - the ability of a patient to adhere for dose, for time, for diet, virally suppressed and attended pharmacy refill. A patient has a combined ART adherence if and only if it fulfills listed indicators. (Patients adhere to self-report, suppressed viral load and Pharmacy refill timely). Otherwise, if they miss one or more indicators they were said to be non-adherent to combined ART adherence. Because patients need to achieve $100 \%$ adherence (near perfect adherence) to ART dose, time, dietary, schedule, pharmacy refill, and viral load.

Combined non-ART Adherence: - the inability of a patient to adhere for dose, for time, for diet, virally suppression and does not attend pharmacy refill.

Baselines CD4 count: - the number of CD4 cells in the blood determines how the immune system is functioning at enrolment time.

Current CD4 count: - the number of CD4 cells in the blood determines how the immune system is functioning currently within 6 months.

Viral Load: - a blood test that counts the amount of HIV in the blood of HIV-infected people who are taking ART service for a minimum of 6 months.

A pharmacy refill record: -Pharmacy refill information can be used to calculate the drug-possession ratio, which represents the maximum possible adherence for a patient over a defined refill period that means if the client collects ART medication within 7 appointment days.

Self-report: - is when patient's report about the adherence of dose, time and food orally

Duration on ART: - is time (duration) of the patient's taking ART medication.

Disclosure status: - is a patient when disclosing their status for family, friend, partner or others for support.

Schedule: - when the patient follows their appointment plan given by health care providers.

Unprotected sex: - sexual intercourse without a condom

Good knowledge: - Those who scored more than calculated mean

Poor knowledge: - Those who scored less than the calculated mean

Adherence level was assessed using a self-reported and patient folder as follows:

The number of doses missed: - follow medication time and dietary instructions and restrictions given by health 
care provider. By using a structured questionnaire (selfreport).

Adhere $=$ if $\leq 2$ doses/30dose or $\leq 3$ dose/60dose, taking no more than $2 \mathrm{hrs}$ before or after the time and follow dietary instructions and restrictions given by health care provider in the past 1 day, 3 days, 7 days, and 1 month properly as prescribed.

Non adhere $=>2$ doses $/ 30$ dose or $>3$ dose/60dose, taking more than 2 hrs before or after the time and not follow dietary instructions and restrictions given by health care provider.

Viral load monitoring: - is one of the most reliable indicators of adherence and can be used as positive reinforcement to encourage continuous adherence. (Good if $<1000$ copies/ $\mathrm{mL}$ (undetectable), poor if $\geq 1000$ copies $/ \mathrm{mL}$ (detectable)

A pharmacy refill: - it is another potential approach for routine adherence monitoring. Pharmacy refill information can be used to calculate the drug-possession ratio, which represents the maximum possible adherence for a patient that means if the Clint collects its ART medication on the appointment day or within 3 days after appointment day.

\section{Data Quality Control}

Data quality was ensured by giving training for data collectors and strict supervision during data collection. A pretest was conducted on $10 \%$ of the sample size in the Nekemte health center before the actual data collection.

\section{Data Processing and Analysis}

Data were checked for completeness and consistency manually. Data entry and coding was done by using Excel and exported to SPSS version 20 for analysis. Descriptive summary using frequencies, proportions, graphs, and cross tabs were used to present results and then bivariate and multivariate logistic regression analysis was made to observe the relative effect of independent variables on the dependent variable by controlling the effect of other variables. P-value $<0.2$ as a cut-off point was taken as a reference to go to the multivariate analysis. Finally, to determine significant association at a 95\% confidence interval and to predict association factors for combined ART level of adherence P-value less than 0.05 was used.

\section{Results}

\section{Socio-Economic Characteristics of the Respondents}

Two hundred eighty-four participants took part in this study with a $100 \%$ response rate. More than half, 159 (56\%) were females. The majority of the respondents, 112 (39.4\%) were between the age group of 25-34 years. The mean age of the respondents was $35.52 \pm 10.1$ years and the range extends from 18 years to 80 years. Regarding marital status, the majority of the respondents, 170 (59.9\%) were married followed by widowed 42 (14.8\%) and divorced 41 (14.4\%). About 107 (37.7\%) had attended secondary school (grades 9-12). Ninety-two(32.4\%) were government employees with their occupation followed by housewives 46 (16.2\%). Concerning religions, the majority of the respondents 131 (46.1\%) were orthodoxly followed by protestant 129 (45.4\%). Regarding ethnicity, the majority, 247 (87\%) were Oromo followed by Amhara 35 (12.3\%). More than half $(52.8 \%)$ earned monthly income of less than 500 Ethiopian Birr (Table 1).

\section{The Clinical Condition of Study Participants}

Seventy percent of study participants have started ART 5 years ago. About 184 (64.8\%) were at WHO stage 3 at ART initiation followed by WHO stage 2, 61 (21.5\%). Regarding the recent treatment stage, almost all (97.9\%) were at treatment stage 1 . This is seen clinically by health care providers. Out of the total 284 participants, 180 (63.4\%) had a baseline CD4 count of below $200 \mathrm{c} / \mathrm{mm} 3$, followed by CD4 count between 200 and $350 \mathrm{c} / \mathrm{mm} 349$ $(17.3 \%)$ at the time of ART initiation. Regarding recent CD4 status of the participants who had been receiving ART for a minimum of 6 months and those CD4 count determination test done within the past 6 months were assessed, that $137(48.2 \%)$ had a CD4 count of $>500 \mathrm{c} /$ $\mathrm{mm} 3$, followed by CD4 count between 200 and $350 \mathrm{c} / \mathrm{mm} 3$ $65(22.9 \%)$.

Out of the total study participants, 224 (78.9\%) had viral load $<1000$ copies/mL, 10 (3.5\%) had $\geq 1000$ copies/ $\mathrm{mL}$ that means detectable viral load and 50 (17.7\%) participants had Unknown result. However, no recent viral load was done for all participants except for those whose VL is $>1000$ copies/mL retest after 3-month adherence counseling. Regarding the schedule for the clinical appointment for the respondents, the majority, 222 (78.2\%) was scheduled for their clinical appointment. Of the total 284 participants, $270(95.1 \%)$ came for a pharmacy refill on their scheduled time within 7 days. About 35 (12.3\%) were suffered from illness during the past 1 month. About 35 patients reported illness in the last month.

Among the 35 participants who were ill in the past month, about $62.9 \%$ reported mild, $22.8 \%$ moderate, and 14.3\% severe illness (Table 2). 
Table I Socio-Demographic Characteristics of HIV-Infected Adults on Chronic HIV Care Follow-Up at Nekemte Referral Hospital, Nekemte, Ethiopia, 2017

\begin{tabular}{|c|c|c|}
\hline Characteristics & Frequency & Percent (\%) \\
\hline \multicolumn{3}{|l|}{ Sex } \\
\hline Male & 125 & 44 \\
\hline Female & 159 & 56 \\
\hline Total & 284 & 100 \\
\hline \multicolumn{3}{|c|}{ Age group (Years) } \\
\hline $18-24$ & 27 & 9.5 \\
\hline $25-34$ & 112 & 39.4 \\
\hline $35-44$ & 84 & 29.6 \\
\hline $45-54$ & 47 & 16.5 \\
\hline$\geq 55$ & 14 & 4.9 \\
\hline Total & 284 & 100 \\
\hline \multicolumn{3}{|l|}{ Marital status } \\
\hline Never married & 31 & 10.9 \\
\hline Married & 170 & 59.9 \\
\hline Divorced & 41 & 14.4 \\
\hline Widowed & 42 & 14.8 \\
\hline Total & 284 & 100 \\
\hline \multicolumn{3}{|l|}{ Literacy status } \\
\hline Illiterate & 41 & 14.4 \\
\hline Read and write & 18 & 6.3 \\
\hline Grade I-8 & 70 & 24.6 \\
\hline Grade 9-12 & 107 & 37.7 \\
\hline Tertiary & 48 & 16.9 \\
\hline Total & 284 & 100 \\
\hline \multicolumn{3}{|l|}{ Occupation } \\
\hline Unemployed & 41 & 14.4 \\
\hline Government & 92 & 32.4 \\
\hline Student & 23 & 8.1 \\
\hline House wife & 46 & 16.2 \\
\hline Driver & 6 & 2.1 \\
\hline Merchant & 39 & 13.7 \\
\hline Others & 37 & 13 \\
\hline Total & 284 & 100 \\
\hline \multicolumn{3}{|l|}{ Religion } \\
\hline Orthodox & 131 & 46.1 \\
\hline Protestant & 129 & 45.4 \\
\hline Muslim & 17 & 6 \\
\hline Catholic & 3 & I.I \\
\hline Others & 4 & 1.4 \\
\hline Total & 284 & 100 \\
\hline \multicolumn{3}{|l|}{ Ethnicity } \\
\hline Amhara & 35 & 12.3 \\
\hline Oromo & 247 & 87.0 \\
\hline Tigre & 2 & 0.7 \\
\hline Total & 284 & 100 \\
\hline
\end{tabular}

Table I (Continued).

\begin{tabular}{|l|l|l|}
\hline Characteristics & Frequency & Percent (\%) \\
\hline Average monthly income (Birr) & & \\
$\leq 500$ & 150 & 52.8 \\
$501-999$ & 14 & 4.9 \\
$\geq 1000$ & 120 & 42.3 \\
Total & 284 & 100 \\
\hline
\end{tabular}

Types of Current ARV Regimen and Level of Adherence in Pts in NRH

Most of the patients, 157 were receiving (TDF $+3 \mathrm{TC}+$ $\mathrm{NVP}), 74$ patients were receiving (AZT $+3 \mathrm{TC}+\mathrm{NVP})$ and 46 and seven (7) patients were receiving (AZT $+3 \mathrm{TC}$ and EVP) and (TDF + 3TC and NVP) respectively.

\section{Knowledge About Antiretroviral Therapy}

Concerning knowledge about ART therapy, more than half of the respondents 191 (67.3\%) had good knowledge about ART therapy.

\section{Social Support to the Respondents}

Almost all of the study participants, 275 (96.8\%) disclosed their status to their friends and/or family members. About 265 (93.3\%) said that they had either a friend and/or a family member that supported them in taking their ARV medications. From 265 study participants who had friends and/or family member to support them, 139 (52.5\%) always got help from them to remember to take HIV medications, Majority of them (94.7\%) mentioned that they used reminder $\mathrm{s}$ to help them to remember taking their ARV medications properly at the right time (Table 3 ).

\section{Perception of Patients' on Their} Relationship with Health Care Providers

Regarding the perception of patients' on their relationship with health care providers almost all, 283 (99.6\%) perceive as health care providers give them appropriate information about the medications. All of the respondents believe as discussing their health problems with health care providers is easy. All of the study participants respond as they are satisfied with the overall support they got from the health care providers. 
Table 2 Clinical Condition Related Characteristics of HIVInfected Adults on Chronic HIV Care Follow-Up at Nekemte Referral Hospital, Nekemte, Ethiopia, 2017

\begin{tabular}{|c|c|c|}
\hline $\begin{array}{l}\text { Clinical Condition } \\
\text { Characteristics }\end{array}$ & Frequency & Percent (\%) \\
\hline \multicolumn{3}{|l|}{$\begin{array}{l}\text { WHO Clinical Staging at ART } \\
\text { Initiation }\end{array}$} \\
\hline WHO Stage I & 25 & 8.8 \\
\hline WHO Stage 2 & 61 & 21.5 \\
\hline WHO Stage 3 & 184 & 64.8 \\
\hline WHO Stage 4 & 14 & 5 \\
\hline Total & 284 & 100 \\
\hline \multicolumn{3}{|l|}{ Recent Treatment Stage } \\
\hline TI & 278 & 97.9 \\
\hline T2 & 3 & I.I \\
\hline $\mathrm{T} 3$ & 2 & 0.7 \\
\hline $\mathrm{T} 4$ & $\mathrm{I}$ & 0.4 \\
\hline Total & 284 & 100.0 \\
\hline \multicolumn{3}{|l|}{ Baseline CD4 } \\
\hline$<200 \mathrm{c} / \mathrm{mm}^{3}$ & 180 & 63.4 \\
\hline $200-350 \mathrm{c} / \mathrm{mm}^{3}$ & 49 & 17.3 \\
\hline $350-500 \mathrm{c} / \mathrm{mm}^{3}$ & 29 & 10.2 \\
\hline$>500 \mathrm{c} / \mathrm{mm}^{3}$ & 26 & 9.2 \\
\hline Total & 284 & 100.0 \\
\hline \multicolumn{3}{|l|}{ Latest CD4(at least 6 month) } \\
\hline$<200 \mathrm{c} / \mathrm{mm}^{3}$ & 34 & 12.0 \\
\hline $200-350 \mathrm{c} / \mathrm{mm}^{3}$ & 65 & 22.9 \\
\hline $350-500 \mathrm{c} / \mathrm{mm}^{3}$ & 48 & 16.9 \\
\hline$>500 \mathrm{c} / \mathrm{mm}^{3}$ & 137 & 48.2 \\
\hline Total & 284 & 100.0 \\
\hline \multicolumn{3}{|l|}{ Duration of ART initiation } \\
\hline 6 month & 9 & 3.2 \\
\hline $7-12$ month & 1 & 0.4 \\
\hline $\mathrm{I}-2$ years & 23 & 8.1 \\
\hline $2-5$ years & 52 & 18.3 \\
\hline$>5$ years & 199 & 70 \\
\hline \multicolumn{3}{|l|}{ Baseline Viral Load } \\
\hline$<1000$ & 224 & 78.5 \\
\hline$\geq 1000$ & 10 & 8.1 \\
\hline Unknown & 50 & 13.4 \\
\hline \multicolumn{3}{|l|}{ Recent Viral Load } \\
\hline$<1000$ & 8 & 2.8 \\
\hline$\geq 1000$ & 9 & 3.2 \\
\hline Unknown & 267 & 94.0 \\
\hline \multicolumn{3}{|l|}{ Appointment Scheduled plan } \\
\hline Scheduled & 222 & 78.2 \\
\hline Un Scheduled & 62 & 21.8 \\
\hline Total & 284 & 100.0 \\
\hline
\end{tabular}

(Continued)
Table 2 (Continued).

\begin{tabular}{|l|l|l|}
\hline $\begin{array}{l}\text { Clinical Condition } \\
\text { Characteristics }\end{array}$ & Frequency & Percent (\%) \\
\hline $\begin{array}{l}\text { Pharmacy refill on Scheduled } \\
\text { Yes }\end{array}$ & 270 & 95.1 \\
No & 14 & 4.9 \\
Total & 284 & 100.0 \\
\hline Sickness in the past one month & & \\
Yes & 35 & 12.3 \\
No & 249 & 87.7 \\
Total & 284 & 100.0 \\
\hline
\end{tabular}

Table 3 Social Supports That the Study Participants Reported Among HIV-Infected Adults on Chronic HIV Care Follow-Up at Nekemte Referral Hospital, Nekemte, Ethiopia, 2017

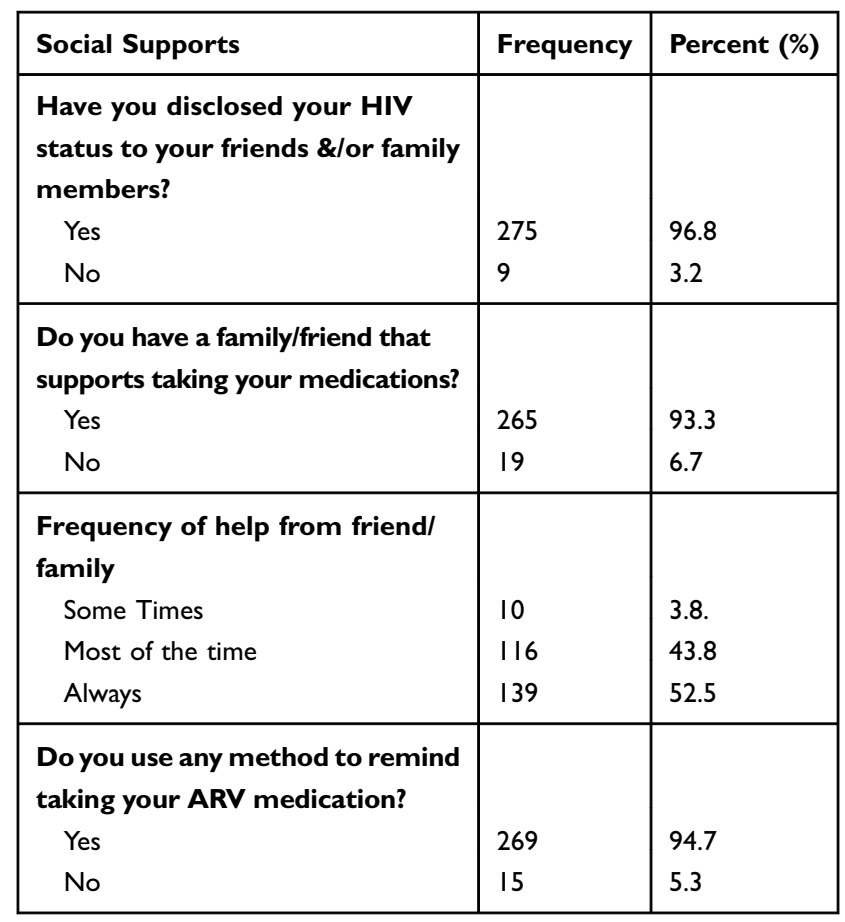

\section{Reasons for Missing ART Medications}

Out of the 72 patients who missed ART medication, 44.4\% of them pointed out their reason as they simply forgot taking the medication and $21 \%$ of the patients mentioned a lack of transportation as a reason for missing the medication (Figure 1).

\section{Health Habits of the Patients}

Majority of the respondents, 43 (15.1\%) ever drunk alcohol from those, $10(23.25 \%)$ drunk alcohol in the past 


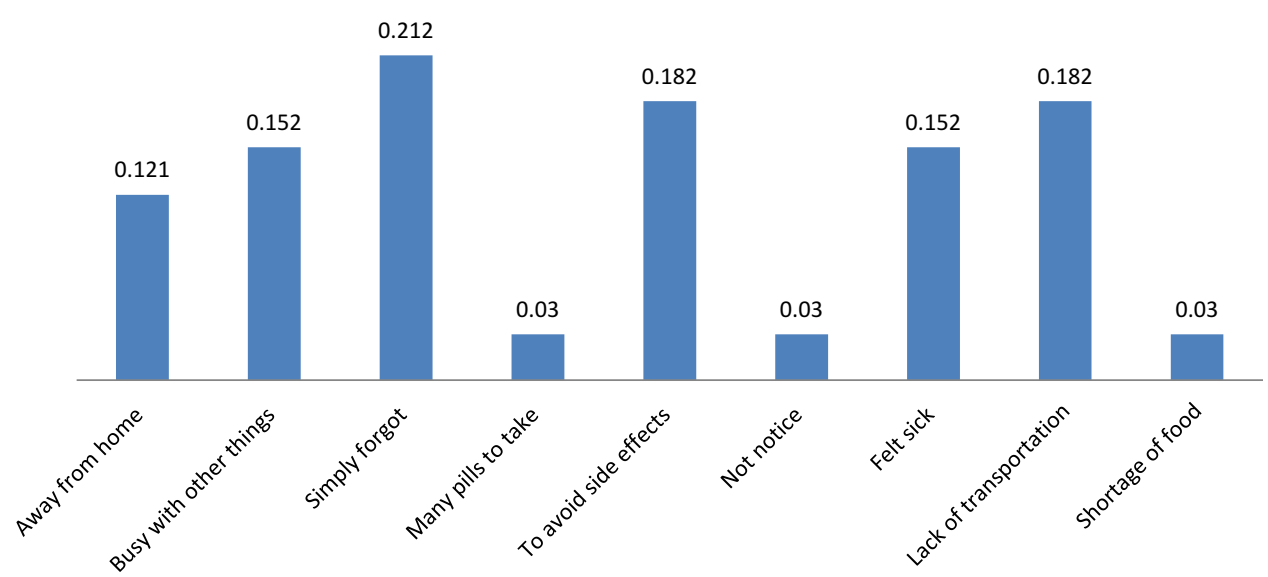

Figure I Reasons for missing ART medication among HIV-infected adults on chronic HIV care follow up at Nekemte Referral Hospital, Nekemte, Ethiopia, 2017.

month. About $34.9 \%$ engaged in unprotected sexual intercourse (Table 4).

\section{Level of Combined ART Adherence}

From a total of 284 respondents, $230(81 \%)$ of them adhered to combined ART and $54(19 \%)$ of them were non-adhered to combined ART (Figure 2).

\section{Factors Associated with Combined ART Adherence}

In bivariate analysis literacy, recent $\mathrm{CD} 4$, baseline viral load, level of knowledge, using reminder and unprotected sexual

Table 4 Health Habits of HIV Patients Among HIV-Infected Adults on Chronic HIV Care Follow-Up at Nekemte Referral Hospital, Nekemte, Ethiopia, 2017

\begin{tabular}{|l|l|l|}
\hline Characteristics & Frequency & Percent \\
\hline $\begin{array}{l}\text { Drunk alcohol ever } \\
\text { Yes }\end{array}$ & $\mathbf{N}=\mathbf{2 8 4}$ & \\
No & 43 & 15.1 \\
\hline $\begin{array}{l}\text { Drunk alcohol in past one month } \\
\text { Yes }\end{array}$ & $\mathbf{N}=\mathbf{4 3}$ & 84.9 \\
No & 10 & 23.25 \\
\hline Smoke cigarette & 33 & 76.74 \\
Yes & & \\
No & 1 & 0.4 \\
\hline Chewed chat in past one month & 283 & 99.6 \\
Yes & 3 & \\
No & 281 & 1.1 \\
\hline Had unprotected sex & & 98.9 \\
Yes & 99 & \\
No & 185 & 65.1 \\
\hline
\end{tabular}

Adherance Non adherance

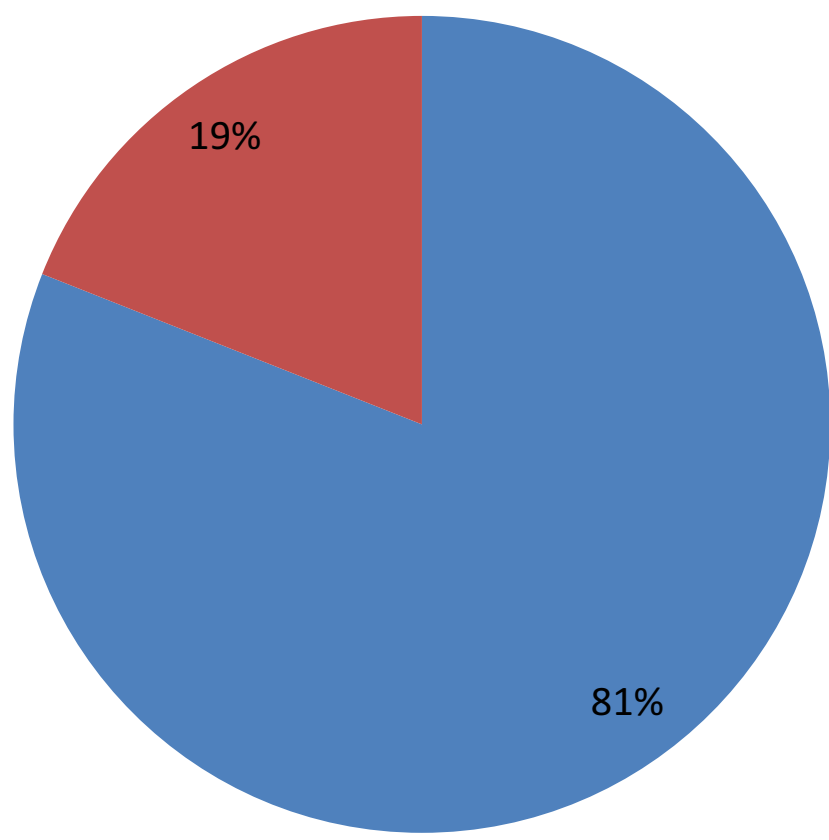

Figure 2 Level of ART adherence among HIV-infected adults on chronic HIV care follow up at Nekemte Referral Hospital, Nekemte, Ethiopia, 2017.

intercourse were significant at P-value less than 0.2. They were considered as candidate variables for multivariate analysis. After adjustment for associated factors for non-adherence to combined ART, factors associated with adherence were level of knowledge on ART $(\mathrm{AOR}=2.79$ $(1.49,5.25)$, using reminder $(\mathrm{AOR}=4.98(1.65,15.02)$ and unprotected sexual intercourse $(\mathrm{AOR}=2.16(1.15,4.05)$.

In this study, participants who have good knowledge were 2.8 times more likely to adhere to combined ART 
Table 5 Factors Associated with Combined ART Adherence Among Adult Patients on ART in Nekemte Referral Hospital, Nekemte, Ethiopia, 2017

\begin{tabular}{|c|c|c|c|c|c|c|}
\hline \multicolumn{2}{|l|}{ Characteristics } & \multicolumn{2}{|c|}{ Combined ART Adherence } & \multirow{3}{*}{$\begin{array}{l}\text { COR(95\% Cl) } \\
1 \\
1.83(0.44,7.57) \\
1.24(0.51,3) \\
1.8(0.77,4.27) \\
2.56(0.85,7.7)\end{array}$} & \multirow{3}{*}{$\begin{array}{l}\text { AOR(95\% CI) } \\
\text { I } \\
\text { I.55(0.345,6.98) } \\
\text { I.35(0.5I,3.57) } \\
\text { I.84(0.736,4.59) } \\
2.69(0.84,8.69)\end{array}$} & \multirow{3}{*}{$\begin{array}{l}\text { P-value } \\
\\
0.56 \\
0.54 \\
0.19 \\
0.09\end{array}$} \\
\hline & & \multirow{2}{*}{$\begin{array}{l}\text { Adherent } \\
30(73.2 \%) \\
15(83.3 \%) \\
54(77.1 \%) \\
89(83.2 \%) \\
42(87.5 \%)\end{array}$} & \multirow{2}{*}{$\begin{array}{l}\text { Non-Adherent } \\
11(26.8 \%) \\
3(16.7 \%) \\
16(22.9 \%) \\
18(16.8 \%) \\
6(12.5 \%)\end{array}$} & & & \\
\hline Educational status & $\begin{array}{l}\text { Illiterate } \\
\text { Read and write } \\
\text { Grade I-8 } \\
\text { Grade 9-12 } \\
\text { Tertiary }\end{array}$ & & & & & \\
\hline Recent CD4 & $\begin{array}{l}<200 \mathrm{c} / \mathrm{mm}^{3} \\
200-350 \mathrm{c} / \mathrm{mm}^{3} \\
350-500 \mathrm{c} / \mathrm{mm}^{3} \\
>500 \mathrm{c} / \mathrm{mm}^{3}\end{array}$ & $\begin{array}{l}25(73.5 \%) \\
54(83.1 \%) \\
36(75 \%) \\
115(83.9 \%)\end{array}$ & $\begin{array}{l}9(26.5 \%) \\
11(16.9 \%) \\
12(25 \%) \\
22(16.1 \%)\end{array}$ & $\begin{array}{l}\text { I } \\
\text { I. } .76(0.65,4.8) \\
\text { I.I }(0.396,2.95) \\
I .88(0.77,4.57)\end{array}$ & $\begin{array}{l}1.69(0.57,5.03) \\
0.94(0.32,2.78) \\
2.22(0.85,5.83)\end{array}$ & $\begin{array}{l}0.34 \\
0.9 \\
0.1\end{array}$ \\
\hline Baseline viral load & $\begin{array}{l}<1000 \\
\geq 1000 \\
\text { Unknown }\end{array}$ & $\begin{array}{l}186(83) \\
8(80 \%) \\
36(72 \%)\end{array}$ & $\begin{array}{l}38(17 \%) \\
2(20 \%) \\
14(28 \%)\end{array}$ & $\begin{array}{l}\text { I } \\
0.817(0.167,4) \\
0.525(0.259,1.07)\end{array}$ & $\begin{array}{l}\text { I } \\
0.926(0.179,4.78) \\
0.58(0.26, I .26)\end{array}$ & $\begin{array}{l}0.93 \\
0.17\end{array}$ \\
\hline Knowledge status & $\begin{array}{l}\text { Good } \\
\text { Poor }\end{array}$ & $\begin{array}{l}165(86.4 \%) \\
65(69.9 \%)\end{array}$ & $\begin{array}{l}26(13.6 \%) \\
28(30.1 \%)\end{array}$ & $\begin{array}{l}2.73(1.49,5.01) \\
I\end{array}$ & $\begin{array}{l}2.79(1.49,5.25)^{*} \\
\text { । }\end{array}$ & 0.001 \\
\hline Used reminder & $\begin{array}{l}\text { Yes } \\
\text { No }\end{array}$ & $\begin{array}{l}223(82.9 \%) \\
7(46.7 \%)\end{array}$ & $\begin{array}{l}46(17.1 \%) \\
8(53.3 \%)\end{array}$ & $\begin{array}{l}5.54(1.91,16.04) \\
1\end{array}$ & $4.98(1.65,15.02)^{*}$ & 0.004 \\
\hline Unprotected sex & $\begin{array}{l}\text { Yes } \\
\text { No }\end{array}$ & $\begin{array}{l}91(74.6 \%) \\
139(85.8 \%)\end{array}$ & $\begin{array}{l}31(25.4 \%) \\
23(14.2 \%)\end{array}$ & $\begin{array}{l}\text { I } \\
2.06(1.13,3.75)\end{array}$ & $2.16(1.15,4.05)^{*}$ & 0.016 \\
\hline
\end{tabular}

Note: *Shows significant association at $\mathrm{P}<0.05$.

compared to those who have poor knowledge. Patients who used a reminder to take medication were 5 times more likely to adhere to combined ART when compared to those who did not use a reminder. Respondents who had protected sexual intercourse were 2.16 times more likely to adhere to combined ART when compared to those who had unprotected sexual intercourse (Table 5).

\section{Discussion}

This study assessed the level of Combined ART adherence and factors affecting ART adherence among HIV-infected adults on chronic HIV care follow up at Nekemte Specialized Hospital. Of the total 284 study participants, 230 (81\%) have combined ART adherence. This result was similar to a study conducted in Addis Ababa (80\%) and Gonder and Felege hiwot hospital (82.7\%) and $83 \%$ in two hospitals of Oromia region. ${ }^{11,15,16}$

This finding is lower than the study conducted in Gobba (90.8\%) DebreMarkos (88.8\%) and Hiwot fana and Jugal hospitals (87\%). ${ }^{12,13,17}$ The difference might be, this study contains combined ART adherence indicators while those studies used only self-report and dose adherence.
The socio-demographic variables such as age, religion, sex, occupation, ethnicity, educational status, marital status, and monthly income were not significantly associated with the level of combined ART adherence. But in a study conducted in Debre Markos monthly income was associated with ART adherence. ${ }^{15}$

In this study, respondents who used a reminder to take medication were 5 times more likely to adhere to combined ART adherence compared to those did not use a reminder. This finding was similar to a study conducted in Nepal which showed the use of a reminder tool is positively associated with ART drug adherence. ${ }^{18}$ Also, a systematic review conducted in sub-Saharan Africa showed the use of memory aids is promoters of ART adherence. ${ }^{19}$ This showed that using the reminder helps them to memorize the time of taking the drug.

The patient's knowledge of ART is important to maximize ART adherence. In this study, participants who had good knowledge about ART medication were 2.8 times more likely to adhere to combined ART adherence compared to those have poor knowledge.

In this study, respondents those had protected sex were 2.16 times more likely to adhere to combined ART when 
compared to those had unprotected sex. This is in line with a study conducted in MACH14 sites which indicated an association between sexual risk behavior and adherence to ART. $^{20}$ Patients who have difficulty in adhering to ART are also vulnerable to engage in risky sexual behaviour.

In this study, forgetting, lack of transportation, fear of side effects, avoiding the notice of others to take medication and illness were the major reasons for not taking ART medication. This is similar to a study conducted in different settings. ${ }^{12,21-23}$

\section{Limitation}

The first limitation comes from the nature of the study design, ie since the study design is a cross-sectional which collects data at a point in time it is difficult to identify existent factors that affect the study. The study was conducted only in the Nekemte Specialized hospital. Because of the single site, the findings may not be generalized to similar clinical settings. Recall bias and social desirability bias are also the possible bias which may encounter in this study. There is no gold standard for measuring adherence.

\section{Conclusion}

The level of Combined ART adherence was $81 \%$. The major reasons for missing doses were simple forgetfulness, lack of transportation wanted to avoid side effects, felt sick or ill, being busy with other things, being away from home. The level of adherence was significantly associated with variables like knowledge on ART, used reminder and engaged in unprotected sexual intercourse.

\section{Data Sharing Statement}

All relevant data are within the manuscript.

\section{Acknowledgments}

We would like to extend our appreciation to Nekemte Specialized Hospital staff and HIV clients for their cooperation and willingness during data collection.

\section{Author Contributions}

All authors contributed to data analysis, drafting or revising the article, gave final approval of the version to be published, and agree to be accountable for all aspects of the work.

\section{Funding}

The authors received no specific funding for this work.

\section{Disclosure}

The authors declare that they have no competing interests.

\section{References}

1. FHAPCO. Monthly HIV Care and ART Update (2012). Addis Ababa: Federal HIV AIDS Prevention and Control Secretariats; 2012.

2. Global HIV/AIDS response epidemic update and health sector progress towards universal access. Progress report. Available from: https://www. who.int/hiv/pub/progress_report2011/en/. Accessed February 21, 2020.

3. Bam K, Rajbhandari RM, Karmacharya DB, Dixit SM. Guidelines strengthening adherence to Anti Retroviral Therapy (ART) monitoring and support: operation research to identify barriers and facilitators in Nepal. BMC Health Serv Res. 2015;15:188. doi:10.1186/ s12913-015-0846-8

4. van Loggerenberg F, Gray D, Gengiah S, et al. A qualitative study of patient motivation to adhere to combination antiretroviral therapy in south Africa. AIDS Patient Care STDS. 2015;29(5):299-306.

5. HIV/AIDS in Ethiopia: The Clinton Health Access Initiative. Available from: https://clintonhealthaccess.org/hiv-aids/. Accessed 2 March 2020.

6. Panel on Antiretroviral Guidelines for Adults and Adolescents. Department of Health and Human Services. Guidelines for the Use of Antiretroviral Agents in Adults and Adolescents Living with HIV. Available from: http://www.aidsinfo.nih.gov/ContentFiles/ AdultandAdolescentGL.pdf. Accessed 2 March 2020.

7. National Comprehensive HIV Prevention, Care and Treatment Guideline of Ethiopia to Address HIV test and Start. Supplement to the 2014 National Comprehensive HIV Prevention, Care and Treatment Guideline of Ethiopia to Address HIV test and Start. Addis Ababa: FMOH; 2016.

8. Springer SA, Dushaj A, Azar MM. The impact of DSM-IV mental disorders on adherence to combination antiretroviral therapy among adult persons living with HIV/AIDS: a systematic review. AIDS Behav. 2012;16(8):2119-2143. doi:10.1007/s10461-012-0212-3

9. Markos E, Worku A, Davey G. Adherence to ART in PLWHA at Yirgalem Hospital, South Ethiopia. Ethiop J Health Dev. 2008;22 (2):174-179.

10. Chesney MA. The elusive gold standard: future perspectives for HIV adherence assessment and intervention. J Acquir Immune Defic Syndr. 2006;43(1):S149-S155. doi:10.1097/01.qai.0000243112.91293.26

11. Bezabhe WM, Peterson GM, Bereznicki L, et al. Adherence to antiretroviral drug therapy in adult patients who are HIV-positive in Northwest Ethiopia: a study protocol. BMJ Open. 2013;3:e003559. doi:10.1136/BMJopen-2013-003559GONDER

12. Bikila L, Kadir H, Tuke G, Mohammed A, Mareg H. Adherence to antiretroviral therapy and associated factors among people living with HIV/AIDS at Gobba Hospital, Southeast Ethiopia. Qual Prim Care. 2015;23(6):336-341.

13. Asmare M, Aychiluhem M, Ayana M, Jara D. Level of ART adherence and associated factors among HIV Sero- positive adult on highly active antiretroviral therapy in Debre Markos Specialized Hospital, Northwest Ethiopia. $J$ Antivir Antiretrovir. 2014;6:120-126. doi:10.4172/jaa.1000107DEBREMARKOS

14. Tiyou A, Belachew T, Alemseged F, et al. Predictors of adherence to antiretroviral therapy among people living with HIV/AIDS in resource-limited setting of southwest Ethiopia. AIDS Res Ther. 2010;7:39. doi:10.1186/1742-6405-7-39

15. Abdissa AE. Determinant Factors Affecting Adherence to Antiretroviral Therapy Among HIV Infected Patients. Adis Ababa; 2013.

16. Awel M. Antiretroviral adherence and its detriments among people living with HIV/AIDS on highly active antiretroviral therapy in two hospitals of Oromia regional state [Ethiopian Public Health Association (EPHA) extract from EPHA-sponsored Master Thesis on HIV/AIDS extract. 4]. Ethiopia; 2008:9-19. 
17. Mitiku H, Abdosh T, Teklemariam T. Factors affecting adherence to antiretroviral treatment in Harari National Regional State, Eastern Ethiopia. Isrn Aids. 2013:Article ID 960954, 7. doi:10.1155/2013/ 960954

18. Shigdel R, L A. A, E. K, Bhandari LA. Factors associated with adherence to antiretroviral therapy in HIV-infected patients in Kathmandu District, Nepal. HIV AIDS. 2014;6:109-116. doi:10. 2147/HIV

19. Heestermans T, Browne JL, Aitken SC, et al. Determinants of adherence to antiretroviral therapy among HIV-positive adults in sub-Saharan Africa: a systematic review. BMJ Glob Health. 2016;1: e000125. doi:10.1136/bmjgh-2016-000125

20. Remien RH, Dolezal C, Wagner GJ, et al. The association between poor antiretroviral adherence and unsafe sex: differences by gender and sexual orientation and implications for scale-up of treatment as prevention. AIDS Behav. 2014;18(8):1541-1547. doi:10.1007/s104 61-013-0656-0
21. Letta S, Demissie A, Oljira L, Dessie Y. Factors associated with adherence to Antiretroviral Therapy (ART) among adult people living with HIV and attending their clinical care, Eastern Ethiopia. BMC Int Health Hum Rights. 2015;15:33. doi:10.1186/s12914-015-0071-X

22. Dibaba B, Hussein M. Factors associated with non-adherence to antiretroviral therapy among adults living with HIV/AIDS in Arsi Zone, Oromia. J AIDS Clin Res. 2017;8:647. doi:10.4172/21556113.1000647

23. Sebsibe T, Ayaleneh T, Wubshet M. Adherence to antiretroviral treatment and associated factors among people living with HIV/ AIDS in Northwest Ethiopia. J Trop Dis. 2014;2:133. doi:10.4172/ 2329-891X.1000133

\section{Publish your work in this journal}

HIV/AIDS - Research and Palliative Care is an international, peerreviewed open-access journal focusing on advances in research in HIV, its clinical progression and management options including antiviral treatment, palliative care and public healthcare policies to control viral spread. The manuscript management system is completely online and includes a very quick and fair peer-review system, which is all easy to use. Visit http://www.dovepress.com/testimonials.php to read real quotes from published authors. 